\title{
Input Methods in Mobile Learning Environments*
}

\author{
Cătălin BOJA ${ }^{\mathbf{1}}$, Alin ZAMFIROIU ${ }^{\mathbf{1 , 2}}$ \\ ${ }^{1}$ Bucharest University of Economic Studies, \\ 6, Piata Romana, 010374 Bucharest 1, Romania, \\ catalin.boja@ie.ase.ro \\ ${ }^{2}$ National Institute for Research \& Development in Informatics, \\ 8-10, Maresal Al. Averescu Blvd., 011455 Bucharest 1, Romania, \\ zamfiroiu@ici.ro
}

\begin{abstract}
The latest figures show a clear growth trend in using mobile devices as applications platform in different socioeconomic domains and mobile application development proves to be a real priority and also a challenge for all software developers. M-Learning describes the use of mobile devices for delivering learning activities but in the light of current mobile technologies development it has a new trend of redefining the learning experience for mobile users. It is the new generation of training models. This paper examines common means of data input for a mobile learning environment. Mobile devices have special features that allow users to have a richer user experience when they interact with the MLearning environment than they normally do with classic computer applications. This paper describes a study on students about preferred input data methods used in mobile learning applications. A prototype platform for M-Learning was developed and tested with students.
\end{abstract}

Keywords: Interaction Control, Input Methods, Mobile Learning Environment, Mobile Devices.

\section{Introduction}

The vigorous emergence of mobile devices and applications in different socio-economic activities have made these devices become ubiquitous in the last years. The mobile devices are grouped by their characteristics into several categories (Ivan et al, 2012):

- basic terminals or simple phones are used for elementary functions such as initiate and receive calls, send or receive SMS;

- feature phones have some special additional functions such as camera, touchscreen, wireless;

- multimedia devices like previous category data have some special functions like a powerful camera, large storage media, video and audio player;

- mobile Internet devices are used mostly for web browsing based on wireless connection;

- fashion terminals have a special design and are similar with multimedia devices;

- smartphones are the most used devices; they have business applications, a very good internet connection and a highresolution of screen

- tablets are small size mobile computers

\footnotetext{
"A previous, shorter version of this paper was presented at the "7th International Conference on Virtual Learning - ICVL2012" with the title "Means of Data Introduction for Mobile Learning Applications".
}

with a touchscreen used for interaction; they differentiate from smartphones through a bigger display size;

In (JacobsMediaBlog, 2013), is estimated that smartphones will rich $80 \%$ penetration in mobile devices market of USA, in April 2014, Figure 1. Also, Gartner (Gartner, 2011) predicts that the use of smartphones and tablets will continue to rise in the next three years to a point at which at least 50 percent of enterprise email users will rely primarily on a browser, tablet or mobile client instead of a desktop client and mobile application development projects targeting smartphones and tablets will outnumber native PC projects by a ratio of 4-to- 1 .

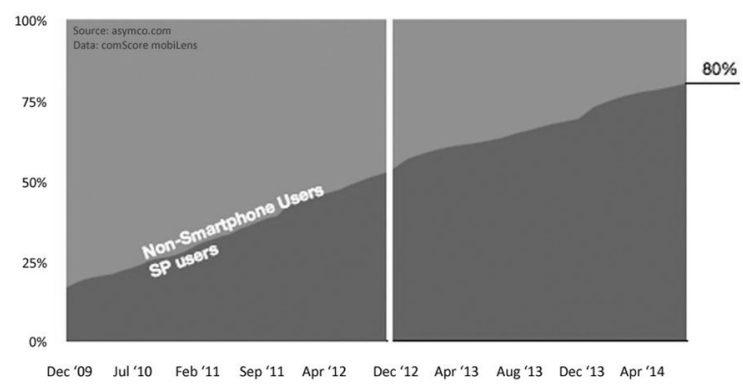

Figure 1. Smartphones penetration. Source: asymco.com

The interaction with mobile devices is realized though different ways such as: (Keinanen, 2011; Wroblewski, 2011; Pocatilu, 2012):

- alphanumerical keyboard characterizes basic terminals; by pressing each button more letters can be written, modification is done by repeatedly pressing; 
- QWERTY keyboard is like a classic keyboard of computers and is specific to more categories of mobile devices such as feature phones, mobile internet devices or smartphones.

- HALF-QWERTY keyboard is a combination of numerical keyboard and QWERTY keyboard; it is specific to feature phones and mobile internet devices; the writing is similar with alphanumerical keyboard, but on this keyboard we don't have so many characters for one key;

- touchscreen represent the technology at which the interaction is done by touching the mobile device display; is used by multimedia devices, smartphones and internet devices with a large screen to allow interaction on a larger area;

- mini-Joistick is present additionally on a keyboard and is used to navigate through the phone menu up, down, left and right; it is specific to multimedia devices, fashion devices and internet devices;

- camera is used to take pictures and to interact with mobile devices between some mobile applications special created for camera; this interaction mean is specific to smartphones; pictures and video sequences can be analysed in order to detect and extract the input for a mobile application; images as bar or QR codes (Wikipedia Q, 2013) are preferred because they are standardised and can be easily scanned for content; video streams can be used for augmented reality type applications;
- voice is used for smartphones and feature phones by voice recognition and speach 2 text activities, (Wikipedia I, 2013), (Wikipedia S, 2013).

In Table 1 are presented the main ways of interacting with mobile devices.

The level of mobile device use is growing due to portability and efficiency in their use and for the possibility to be used anywhere and anytime. This allows the access to information regardless of time and space.

\section{Related Work}

In (Dumitrache, 2012) five generations of training models are presented:

- correspondence model;

- multimedia model;

- tele-learning model;

- flexible learning model;

- intelligent and flexible learning model.

Added to these is the new learning model: smart, mobile and flexible learning model, which is specific to students who want to have access to information regardless of time and space constraints. This model is characterized by the extensive use of smartphones and tablets for accessing course contents and resources, keeping contact with other users and involving in interactive tasks, as collaborative projects or online assessments. Figure 2 describes the mobile learning environment that is defined on this learning model.

Table 1. Data input means of mobile devices

\begin{tabular}{|c|c|c|c|c|c|c|c|}
\hline & $\begin{array}{l}\text { Basic } \\
\text { terminals }\end{array}$ & $\begin{array}{l}\text { Feature } \\
\text { phones }\end{array}$ & $\begin{array}{l}\text { Multimedia } \\
\text { devices }\end{array}$ & $\begin{array}{l}\text { Mobile } \\
\text { internet } \\
\text { devices }\end{array}$ & $\begin{array}{l}\text { Fashion } \\
\text { terminals }\end{array}$ & Smartphones & Tablets \\
\hline $\begin{array}{l}\text { Alphanumerical } \\
\text { keyboard }\end{array}$ & $\mathrm{X}$ & & & & $\mathrm{X}$ & & \\
\hline QWERTY keyboard & & $\mathrm{X}$ & & $\mathrm{X}$ & & $\mathrm{X}$ & \\
\hline $\begin{array}{l}\text { HALF-QWERTY } \\
\text { keyboard }\end{array}$ & & $\mathrm{X}$ & & $\mathrm{X}$ & & & \\
\hline Touchscreen & & & $\mathrm{X}$ & $\mathrm{X}$ & & $\mathrm{X}$ & $\mathrm{X}$ \\
\hline Mini-Joistick & & & $\mathrm{X}$ & $\mathrm{X}$ & $\mathrm{X}$ & & \\
\hline Camera & & & $\mathrm{X}$ & & & $\mathrm{X}$ & $\mathrm{X}$ \\
\hline Voice & & $\mathrm{X}$ & & & & $\mathrm{X}$ & $\mathrm{X}$ \\
\hline
\end{tabular}




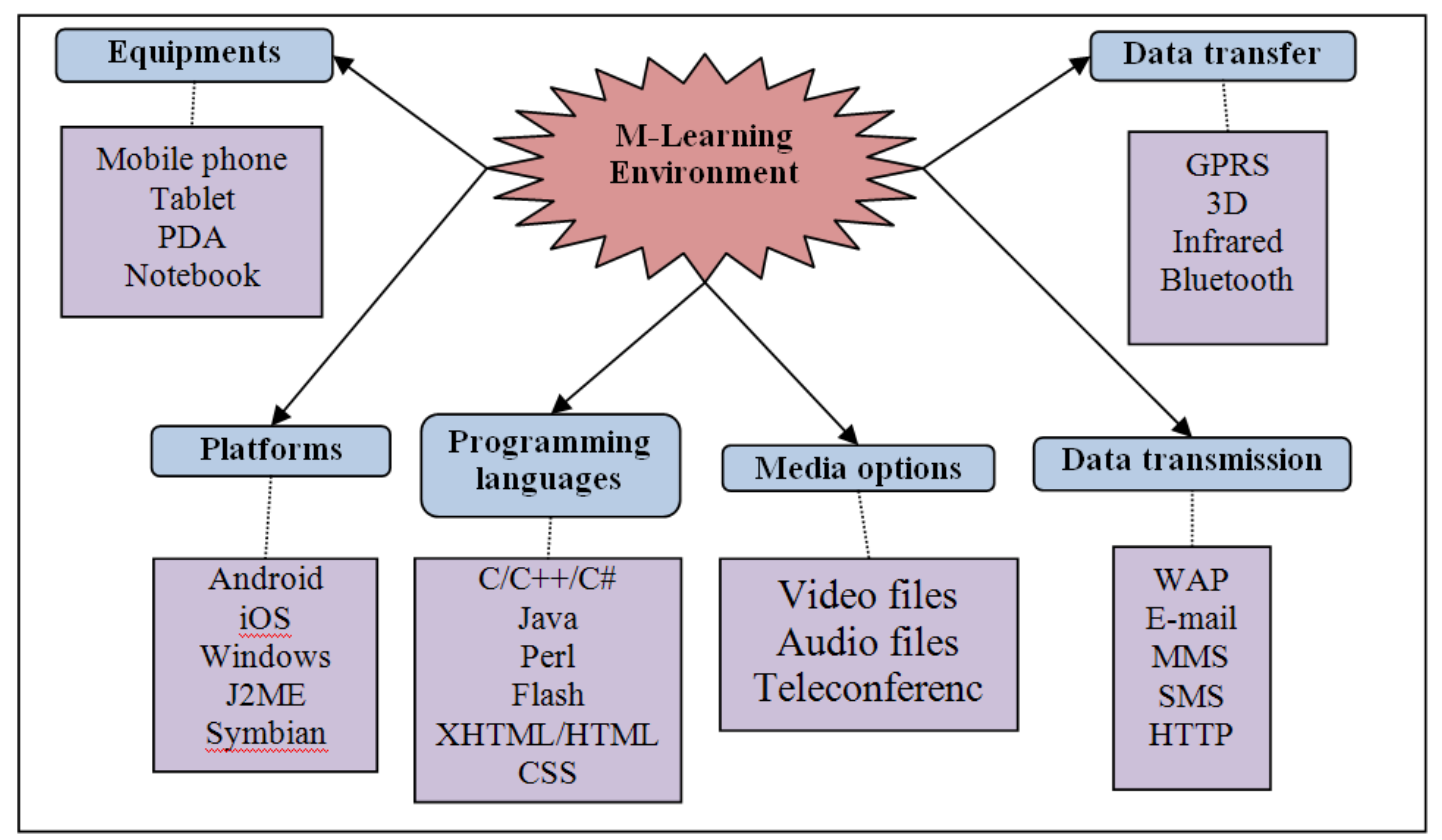

Figure 2. Mobile Learning Environment

According to (Obisat and Hattab, 2009; Ghazvini et al, 2011; Lee and Salman, 2012) M-Learning or E-Learning on mobile is defined as the Science in Hand and represent a new trend of learning mode, defined as the sixth generation.

In (Thorsteinsson and Niculescu, 2012), researchers describe the advantages of using smartphones in homework activity for young students. In this way students are able to use all capabilities of smartphones such as taking photographs or submitting information about a problem, sharing online information and accessing information from Internet through smartphones.

In (Ling, 2005) a statistical analysis about SMS usage in several aspects such as the type and frequency of words used is presented.

The most used word in the messages analyzed, was $D u$ (translated from Norwegian language: you). The second most used word was jeg (translated from Norwegian language: I).

Another dimension considered is the length of words and messages. Data analysis shows that women send messages with 6.95 average words per message and men with 5.54 words per message. Approximately $82 \%$ of the messages do not contain capitalized letters, $11 \%$ contain only capitalized the first letter of the message, and $7 \%$ have a complex capitalized letters for every sentence and for every name of person, street or institution.

Despite their versatility as application platform, mobile devices impose the following restrictions on mobile applications:

- $\quad$ small size of the display, varying from 2.6 in up to 10 in with different resolutions;

- reduced battery life cycle, lasting from several hours to a few days, depending on the applications processing and communications needs;

- reduced capacities for data input.

In recent years, drawbacks such as reduced computing power or limited memory capacity have been overcome by the mobile industry and now mobile devices can fulfil any application requirements for processing power, graphics or data storage. Today, a mobile quad core processor has more computer power than all of NASA back in 1969 when it sent two astronauts to the moon, (Kaku, 2011). Other technologies as mobile communications and data transfer have allowed mobile devices to become efficient clients in distributed cloud architectures that provide rich media content.

The current development of the communications infrastructure and cloud services has dissolved the limits of data storage, as content is stored in cloud and supplied to users on demand. 
For that mobile learning application should provide a simplistic and natural interface. The content of courses should be adapted for the mobile application so that all the tools of the device may be easy to read and use.

The proposed model in (Ribon et al, 2013) enables the access to the learning services through a common interface, such as the learning offered through mobile devices. This model allows the virtual platforms to be viewed as a service and to be structured through the various learning resources.

Another viewpoint for analyzing mobile input methods is to take into consideration types of data needed by M-Learning applications, described in Table 2.

Table 2. Data types for mobile input.

\begin{tabular}{|l|l|l|}
\hline Data type & Input method & Used Module \\
\hline Text & $\begin{array}{l}\text { Manual/ } \\
\text { Automatic } \\
\text { Physical or virtual } \\
\text { keyboard } \\
\text { Speech to text apps } \\
\text { Physical or virtual } \\
\text { keyboard }\end{array}$ \\
\hline Image & Manual & Built in camera \\
\hline Video & Automatic & Built in camera \\
\hline Voice & Automatic & Built in microphone \\
\hline $\begin{array}{l}\text { Location data } \\
\text { GPS/area } \\
\text { coordinates }\end{array}$ & Automatic & Built in GPS module \\
\hline Environment data & Automatic & Built in accelerometer \\
\hline
\end{tabular}

For some of them, mobile devices and their built in modules provide a greater efficiency and flexibility in terms of acquisitions and transmission. For example, M-Learning has adopted location based services (LBS), (Virrantaus et. al., 2001) because most mobile devices have the capability to get the user location and these has opened new ways of providing education services.

\section{Survey Analysis Regarding the Interaction with Mobile Devices}

The collectivity $A=\left\{A_{1}, A_{2}, \ldots, A_{N A}\right\}$, was questioned on how they prefer to interact with mobile phones. Interrogation was conducted through a questionnaire with questions about occupation, experience in using mobile phones and the preferred method of interaction. The collectivity contains 281 people, $\mathrm{NA}=281$.

The collectivity was composed primarily of students, pupils and persons from a learning system, Figure 3.

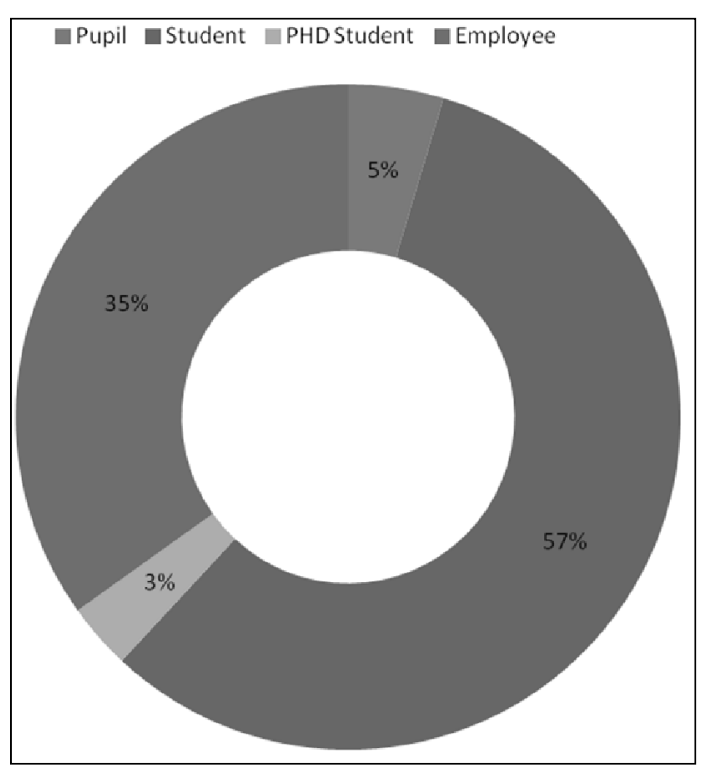

Figure 3. Occupation of respondents

The collectivity has many years of experience in using the mobile devices, Figure 4. Many of respondents have had mobile phones for seven to nine years.

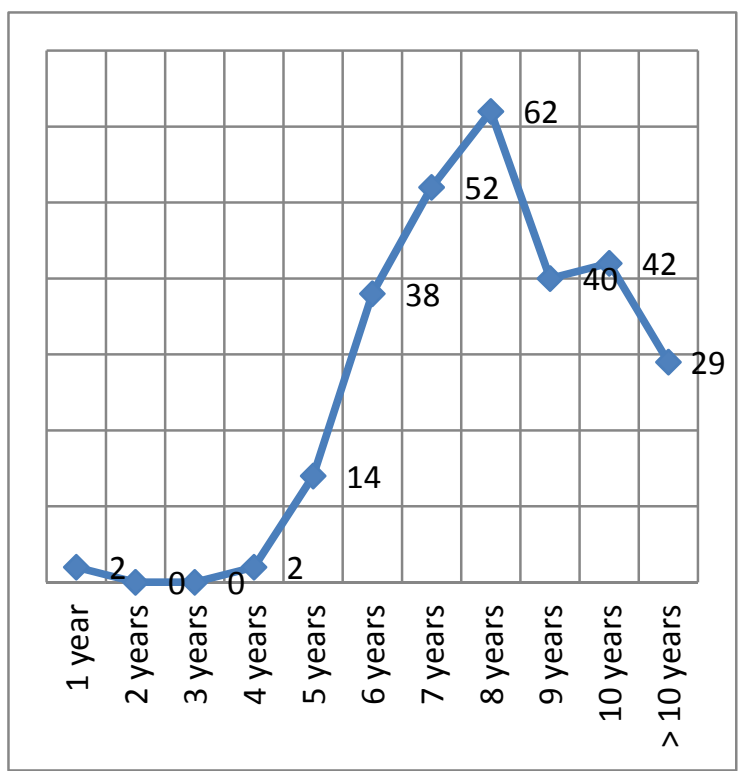

Figure 4. Experience with a mobile phone

Today the experience with mobile phones is not an issue as the average student has a strong experience in using computers, Internet services and mobile devices. Even if they have a basic terminal or a simple phone and lack the financial resources for acquiring a high-end mobile device, they are capable to accommodate very fast with new devices from other category of terminals.

The last question and most important was about which means they prefer to use the most when 
Table 3. Methods of interaction with a mobile phone

\begin{tabular}{|l|r|}
\hline Way of interact & No. of answers \\
\hline Alphanumeric keyboard & 64 \\
\hline QWERTY keyboard & 72 \\
\hline HALF-QWERTY keyboard & 9 \\
\hline Touchscreen & 132 \\
\hline Mini-Joistick & 0 \\
\hline Camera (QR-code) & 1 \\
\hline Voice & 3 \\
\hline
\end{tabular}

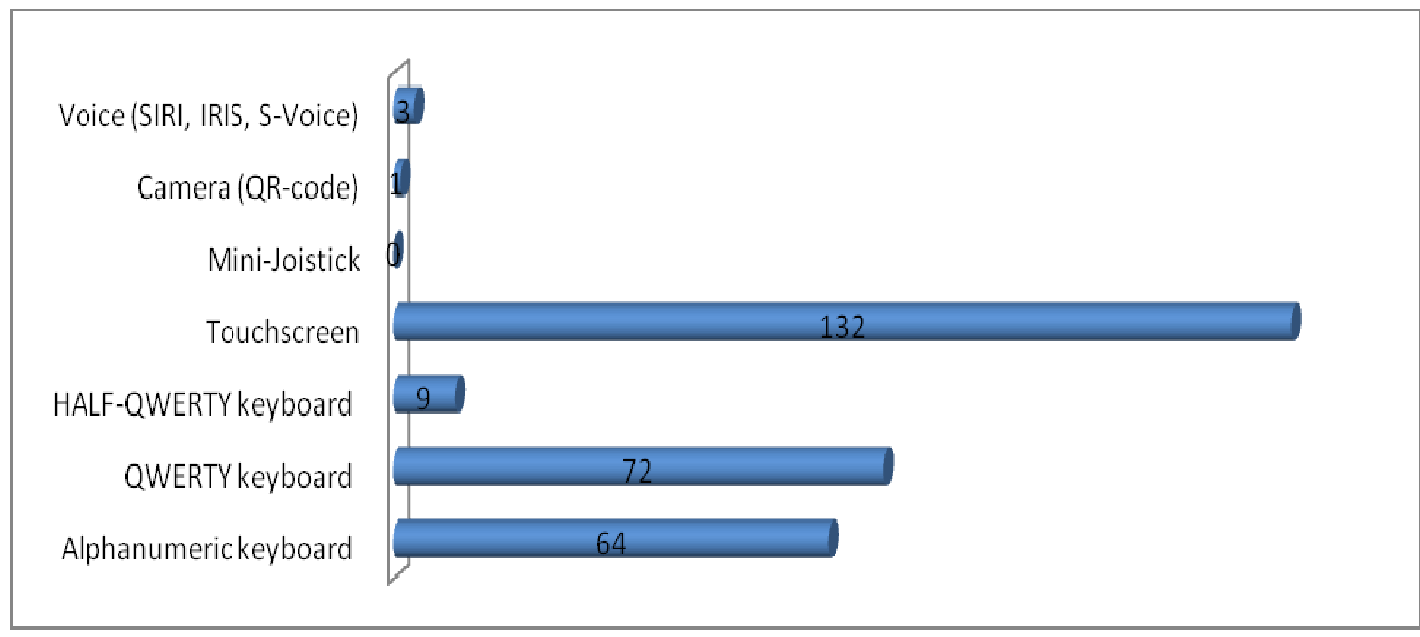

Figure 5. Results for means of interaction with a mobile phone

interacting with their mobile devices. The evaluated methods were those presented at the beginning of this paper.

The results of this survey are presented in Table 3 (graphically represented in Figure 5). Only the mini-joystick has no users.

The most used interaction way is the touch screen. It is followed by QWERTY keyboard and alphanumeric keyboard. Another explanation of the survey result is that the latest generations of smartphones have discarded the physical keyboard in favor of the touch-screen.

According to this study, touch-screen is the most common method of interaction with mobile devices. As most of the respondents are students or pupils, these results are representative for the education system. Thus it is recommended that developed applications in the mobile learning environment be controlled by using these methods of interaction.

\section{Mobile Web Learning Application}

The prototype developed is a mobile learning (M-Learning) platform designed for mobile devices. It is available at zamfiroiu.ici.ro address. Application characteristics are:

- easy to use for all users, the interface is intuitive and even if the user doesn't read the documentation of the application, he/she can very easily interact with it.;

- using through mobile devices, is an application developed to be used on mobile devices; controls used have a reduced dimension special for that;

- available for all mobile browsers; it was tested on minimum ten browsers and different platforms;

The server application is realized in PHP and MySQL. The application is split in two parts, 
according to Figure 6 . The difference is made when the user is logged. Based on the user type and role, it is redirected to the corresponding page. There are two sections: keyboard. The structure of the prototype application is presented in Figure 6 .

To access the platform the users have to write the address link zamfiroiu.ici.ro or to scan the

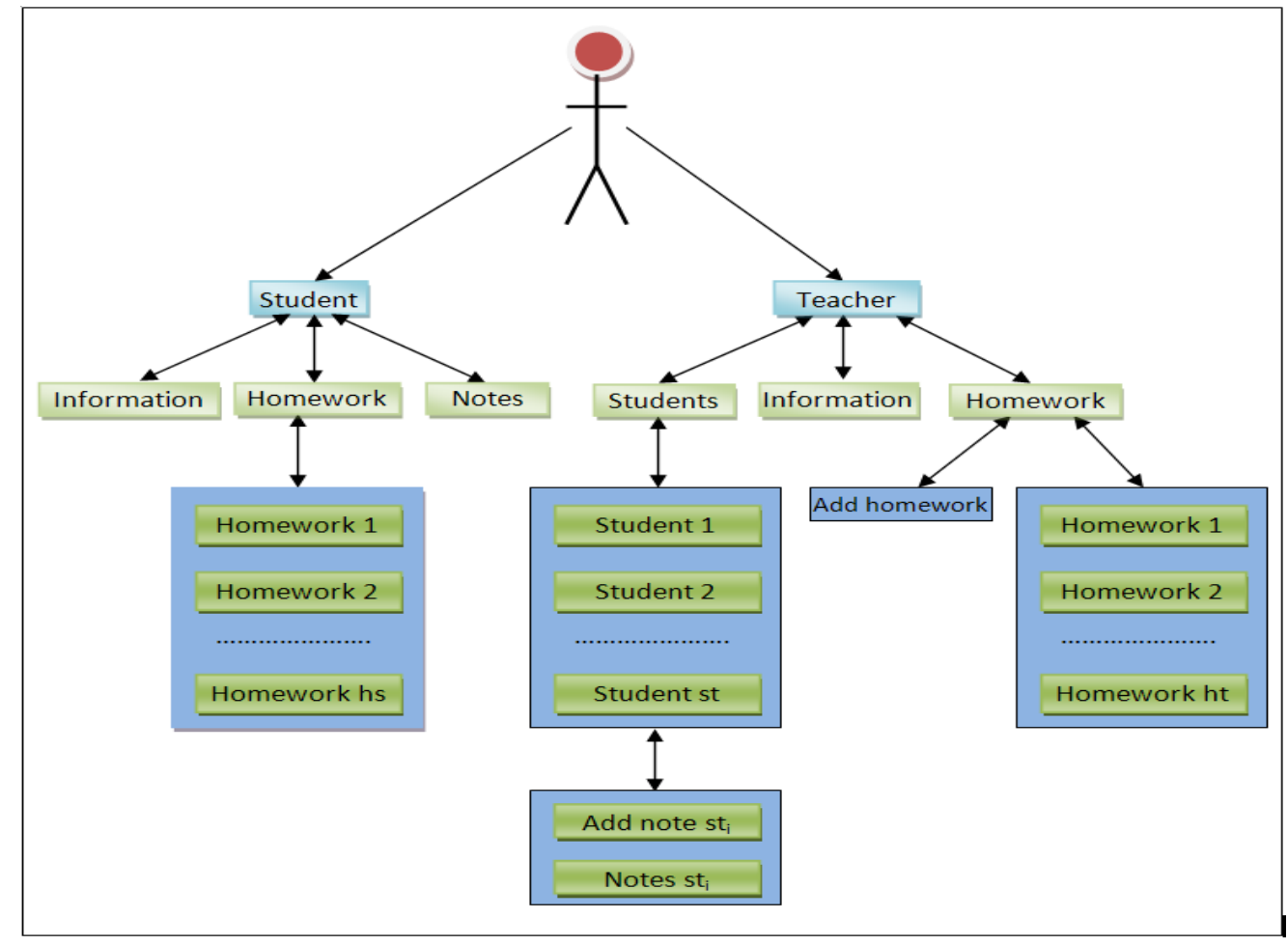

Figure 6. Structure of mobile web learning application

A teacher section where users manage:

- information about him/her;

- a list of students;

- general information about every student;

- the grades for every student;

- available homework uploaded on platform;

- unavailable homework uploaded on platform.

The teacher user is able to:

- add a new note for students;

- upload a new homework on platform;

- make available an unavailable homework.

The second section is the student section (to which student users are redirected). Here, the users may see the following on the platform:

- general information about the user;

- available homework;

- his grades.

The interaction in the application is made though touch-screen and to write information which will be saved is made with QWERTY
QR-code (Wikipedia, 2013) created special for this platform to facilitate the access to the platform, Figure 7.

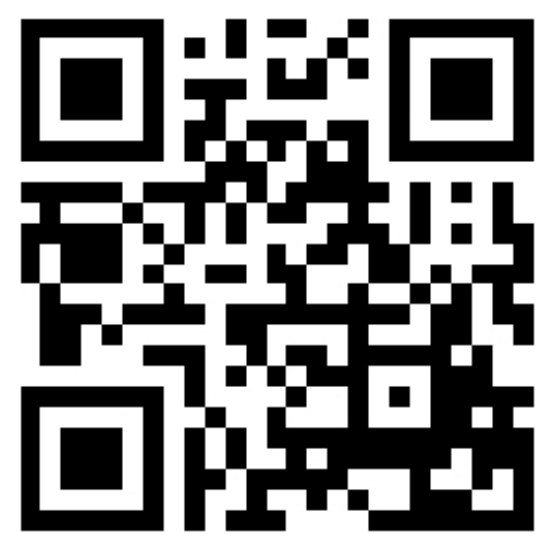

Figure 7. QR-Code to access the platform

The user has to scan this QR-code and will be redirected to the login page of the platform. After login he/she will be redirected to the corresponding page: teacher or student.

The application was tested on a total of 32 students. They had the QR-code image for access the platform. They also had the URL address for those who don't have a QR-code reader application. 
A number of 67 logins were registered. Thus each student logged in twice on average. Access to the platform was achieved through QR code 32 times. This leads to the fact that nearly half of the visits were made via QR code for faster access to the platform.

Sections accessed by the students were viewing the profile and view notes.

In Table 4 mobile devices and mobile browsers used by users to connect to MLearning platform are presented. For each manufacturer of mobile devices the used browsers are presented.

Table 4. Automatic results on M-Learning platform

\begin{tabular}{|l|ll|}
\hline \multicolumn{1}{|c|}{ Device } & \multicolumn{1}{c|}{ Browser } \\
\hline Samsung & - & Android Browser \\
& - & Opera Mini \\
& - & Opera Mobile \\
& - & NetFront \\
& - & Dolfin \\
\hline Nokia & - & Opera Mobile \\
& - & Opera Mini \\
& - & NokiaBrowser \\
& - & UCWeb \\
\hline Apple & - & Safari \\
& - & CriOS \\
\hline BlackBerry & - & BlackBerry Browser \\
\hline HTC & - & Safari \\
& - & Opera Mini \\
& - & Opera Mobile \\
\hline
\end{tabular}

These statistics were taken and used in order to improve the access to the platform only for mobile devices. If the user is connected to the platform on a PC or other device, access was restricted and the user was advised to use a mobile device.

The source code from Figure 8 is used to determine if the visitor of site is from mobile device or not. The list of operating systems is created after the empirical analysis on data from Table 4 and the order in that list also. At start of list it should be the general operating system such as Nokia and at the end of the list it should be the specific operating systems such as series60, series40. In the search first time is selected the Nokia operating system and after is selected the series 60 or series 40 with greater accuracy.

If the visitor is a computer user is redirected to computer.php page. This page is created with the message for users to use mobile device to access the platform.

\section{Interaction Speed}

It was developed a simple questionnaire with six questions to which users respond more quickly without stand to think. Responses were received initially by Textbox controls and then the users will respond to the same questions but through RadioButton controls. For each questionnaire completion was saved the type of device and the necessary time to complete the questionnaire. The types of devices could then complete questionnaires are:

- computer;

- laptop;

- tablet;

- phone.

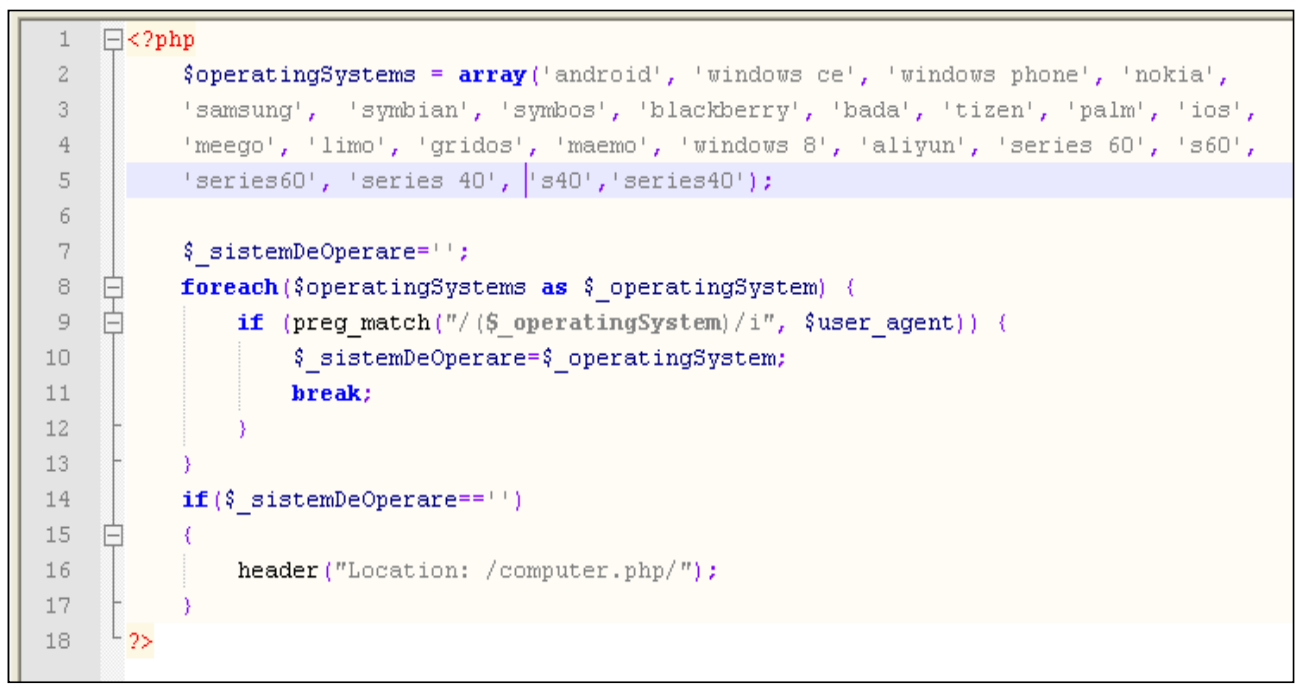

Figure 8. Redirecting to computer version 
After filling of questionnaires by users and the analysis results were obtained an average response on the questionnaire completion in seconds. For each type of device is obtained an average. The data is presented in Table 5 and is plotted in Figure 9. receiving calls and sending / receiving short text messages to devices with processing power similar to that of classical computers and used in all daily activities of users.

Therefore mobile devices penetrate all environments in which electronic devices are

Table 5. Measurements regarding interaction

\begin{tabular}{|l|r|r|}
\hline & Textbox & \multicolumn{2}{|c|}{ RadioButton } \\
\hline Computer & 31,5 & 20,2 \\
\hline Laptop & 33,7 & 23,8 \\
\hline Tablet & 40,3 & 25,7 \\
\hline Phone & 44,8 & 28,8 \\
\hline
\end{tabular}

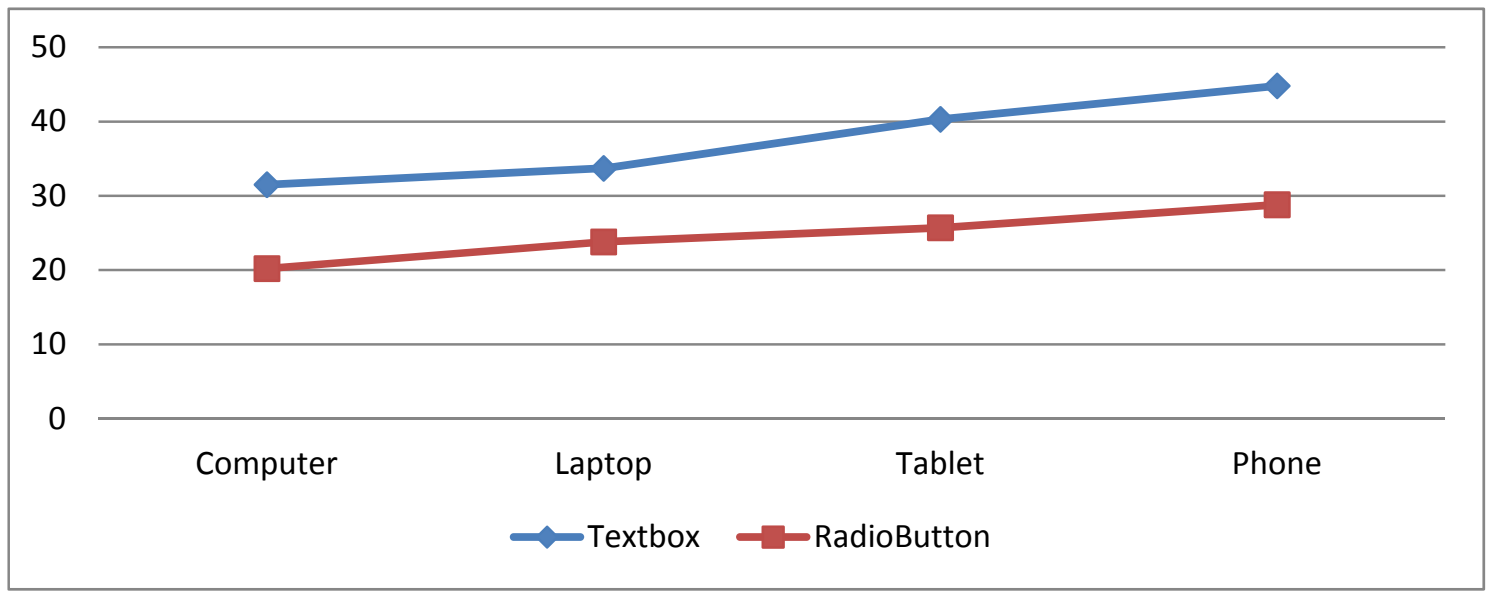

Figure 9. Interaction speed average

Major differences are observed between the use of controls such as Textbox and use controls such RadioButtons. Interaction speed is improved so much that if the data entry on a computer or laptop is made through Textbox controls and from mobile phone is made through RadioButtons controls, interaction time is equal to or even better.

For this it is recommended that the development of applications for mobile devices to use RadioButtons controls in user interaction to increase the interaction speed and decrease the interaction time.

\section{Conclusions}

Mobile devices have evolved greatly in recent years from simple devices used for making and used. In education also mobile devices are widely used.

For an intended use the most suitable user interaction with mobile applications should be closely controlled.

The questionnaire was carried out among of students, pupils and people activates in the educational environment. Thanks to this reason, the results are representative and show the user requirements of mobile applications in the mobile learning environment.

The results of the questionnaire are used to control user interaction with mobile devices used within educational systems.

Prototype application fulfills the conditions of user interaction and was developed respecting the principle of M-Learning. 


\section{Acknowledgement}

A previous, shorter version of this paper was presented at the "7th International Conference on Virtual Learning - ICVL2012" with the title "Means of Data Introduction for Mobile Learning Applications".

\section{REFERENCES}

1. CRANE, L., P. BENACHOUR, P. COULTON, Virtual Learning Environments For Mobile Learning: Constrained By Infrastructural And Sociological Boundaries?, ITALICS, vol. 10(1), February, 2011.

2. DUMITRACHE, M., Sisteme multimedia pentru invatarea on-line, Targoviste, 2012, 194 pg.

3. GHAZVINI, F., R. EARNSHAW, A. MOEINI, D. ROBINSON, P. EXCELL, From E-Learning to M-Learning - The use of Mixed Reality Games as a New Educational Paradigm, International Journal of Interactive Mobile Technologies, vol. 5(2), 2011, pp 17-25.

4. GARTNER, Inc., Gartner Reveals Top Predictions for IT Organizations and Users for 2012 and Beyond, 2011, available online at http://www.gartner.com/newsroom/id/1862 714

5. JACOBS, F., Reach 2.0, available online at http://jacobsmediablog.com/2013/01/16/rea ch-2-0/, last accessed 2013.

6. KAKU, M., Physics of the Future: How Science Will Shape Human Destiny and Our Daily Lives by the Year 2100, ISBN 978-0-385-53080-4, Random House, New York, 2011

7. IVAN, I., C. BOJA, A. ZAMFIROIU, SelfHealing, Quality Characteristic of Mobile Applications, In Proceedings of 19th International Economic Conference IECS 2012, 15-18 June, Sibiu, România.

8. KEINANEN, L. M., Touch Screen Mobile Devices Invading the Internet: UX Guidelines Towards One Web, School of Electrical Engineering, 2011.
9. LEE, K. B., R. SALMAN, The Design and Development of Mobile Collaborative Learning Application Using Android, Journal of Information Technology and Application in Education, vol. 1(1), 2012, pp. 1-8.

10. LING, R., The socio-linguistics of SMS: An analysis of SMS use by a random sample of Norwegians, Mobile Communications, pp. 335-349, 2005.

11. OBISAT, F., E. HATTAB, A Proposed Model for Individualized Learning through Mobile Technologies, International Journal of Communications, vol. 3, nr. 1, 2009.

12. POCATILU, P., Programarea Dispozitivelor Mobile, ASE, Bucharest, 2009.

13. RIBON, J. R., L. J. GARCIA VILLALBA, T. KIM, Application of Mobile Technology in Virtual Communities with Information of Conflict-Affected Areas, Studies in Informatics and Control, vol. 22, issue 1, 2013, ISBN 1220-1766, pp. 33-42.

14. SAYIN, Z., N. ALLAHVERDI, Mobile Training Components and a Model Application, In Proceedings of the International Conference On E-Learning And The Knowledge Society, ELearning'11, 25-26 August, 2011, Bucharest, Romania, ASE Publishing House, Bucharest Romania, pp. 197-202.

15. THORSTEINSSON, G., A. NICULESCU, Using Mobile Technology for Problem Need Identification in School-aged Children Environment, Studies in Informatics and Control, vol. 21, issue 4, 2012, ISBN 1220-1766. pp. 431-438.

16. VIRRANTAUS, K., H. TIRRI, J. VEIJALAINEN, J. MARKKULA, A. KATANOSOV, A. GARMASH, V. TERZIYAN, Developing GIS-Supported Location-Based Services, WISE, vol. 2, pp.0066, Second International Conference on Web Information Systems Engineering (WISE'01) Volume 2, 2001. 
17. VUCETIC, Z., B. ODADZIC, Mobile School Service (MSS), International Journal of Interactive Mobile Technologies, vol. 4, nr. 2, 2010, pp. 29-33.

18. WIKIPEDIA Q, QR Code, available online at http://qrcode.kaywa.com/, last accessed on 2013.
19. WIKIPEDIA I, IRIS software, online at http://en.wikipedia.org/wiki/Iris (software), accessed on 2013

20. WIKIPEDIA S, SIRI Software, online at http://en.wikipedia.org/wiki/Siri_(software) , last accessed on 2013

21. WROBLEWSKI, L., Mobile First, New York, 2011 